Некоторые закономерности климатических и экосистемных изменений в Сибири

\author{
Михаил В. Кабанов* \\ Институт мониторинга климатических \\ и экологических систем СО РАН, \\ 634055 Россия, Томск, пр. Академический, 10/3 ${ }^{1}$
}

Received 26.11.2008, received in revised form 3.12.2008, accepted 10.12.2008

В результате статистического анализа накопленных в мировой сети инструментальных данных выявлены закономерности наблюдаемых климатических и экосистемных изменений в Сибирском регионе. Показано, что потепление в Сибири за последний климатический (30-летний) период характеризуется неоднородной субрегиональной структурой с мезомаситабными очагами ускоренных темпов потепления до $0,5{ }^{\circ} \mathrm{C} / 10$ лет. Тренды приземного атмосферного давления за тот же период имеют менее контрастную субрегиональную структуру с уменьшением среднегодового давления до 0,2-0,4 Гпа/10 лет.

Во временной изменчивости климатических параметров за прошедшее столетие по результатам вейвлет-анализа выделены масштабы периодичностей в 10-12 и в 30-50 лет. По вейвлетспектрам для приземной температуры Западной Сибири и индекса Северо-Атлантического колебания выявлена их корреляционная связь в 1940-1990 гг. с временным сдвигом до семи лет в отдельные годы. Этот климатический феномен объясняется возможными инерционными механизмами океанического переноса тепла.

По результатам анализа наземных и аэрокосмических инструментальных наблюдений обсуждаются климатические эффекты сибирских болот (на примере Большого Васюганского боло$m a)$.

Ключевые слова: изменения климата, экосистемные изменения, карта потепления, вейвлетанализ, Большое Васюганское болото.

\section{Введение}

При исследованиях глобальных и региональных природно-климатических изменений встает беспрецедентно сложная проблема, состоящая в том, что взаимосвязанные наблюдаемые изменения окружающей среды и климата не поддаются объяснению в рамках простой парадигмы «причина-следствие» (Амстердамская декларация, 2001). Более того, при описании этих изменений необходимо учитывать, что многие климатообразующие факторы космофизического (в том числе гелиосферного), геосферного, биосферного и антропогенного происхождения определяют не только изменения состояний природно-климатической системы, но и специфическую для разных регионов эволюцию тех физических процессов и явлений, которые лежат в основе этих изменений.

\footnotetext{
* Corresponding author E-mail address: kabanov@imces.ru (C) Siberian Federal University. All rights reserved
} 
Результаты интенсивных научных исследований в последние годы в рамках международных, национальных и региональных программ привели к выводу о том, что интегрированные (мультидисциплинарные) региональные исследования следует признать приоритетными (International Geosphere - Biosphere Programm II..., 2002). При таких исследованиях становится необходимой как регионализация существующих математических моделей глобального климата, так и организация комплексных инструментальных наблюдений большего числа одновременно измеряемых параметров. Пока сопряжение двух научных подходов (математического моделирования и регионального мониторинга) при совместных исследованиях наталкивается на нерешенные проблемы, ряд из которых отмечен в (Кабанов, Лыкосов, 2006).

Ниже обсуждаются некоторые результаты анализа наземных и аэрокосмических инструментальных данных для Сибири, которые выявили региональные и субрегиональные (мезомасштабные) особенности наблюдаемых природно-климатических изменений, а также их динамические особенности (временные масштабы).

\section{Ретроспектива региональных изменений}

Современные научные знания об эволюции системы Земля дают основания для ретроспективного взгляда на региональные особенности климатических и экосистемных изменений в свете взаимодействия глобальных и региональных процессов на планете. Историческое прошлое Сибири на шкале геологического времени удается выделить, и оно оказывается особенно впечатляющим.

Эволюция твердого тела Земли в геологическом прошлом приводила к кардинальным изменениям региональных природноклиматических систем. Геологический этап, когда происходил дрейф континентов (Ушаков, Ясаманов, 1984), может считаться начальным для появления Сибирского региона планеты. На рис. 1 представлены отдельные фрагменты из карт исторической геологии по (Подобина, Родыгин, 2000, Monroe, Wicander, 1994), на которых обозначен континент, выделяемый как Сибирь. Как видно на рис. 1, из первоначального географического положения в Южном полушарии Сибирь в последующем дрейфовала в Северное полушарие со смещением на восток. Естественно, что при таком дрейфе на протяжении нескольких климатических эпох в Сибири, как и в других регионах, происходили кардинальные природноклиматические изменения.

Современные высокоточные инструментальные наблюдения фиксируют продолжающиеся заметные (за пределами ошибок наблюдения) изменения положения континентов и рельефа земной поверхности (Трубицын, 2005). Эти и другие геосферные процессы (извержения вулканов, землетрясения, тепловые потоки в литосфере и др.) относятся к числу природных факторов, которые продолжают оказывать существенное влияние на современные климатические и экосистемные изменения. Поэтому исследования этого климатически значимого фактора остаются актуальным разделом для современной климатологии, в том числе и для интегрированных региональных исследований.

\section{Пространственные масштабы наблюдаемых изменений}

Масштабы пространственной неоднородности наблюдаемого потепления в Сибири были определены по результатам анализа линейного тренда среднегодовой приземной температуры. Расчет этого линейного тренда проводился по накопленным рядам среднемесячных температур за вторую половину XX 


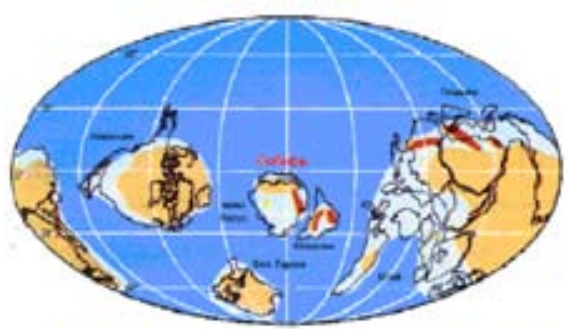

523-505 млн лет назад (Кем6рий)

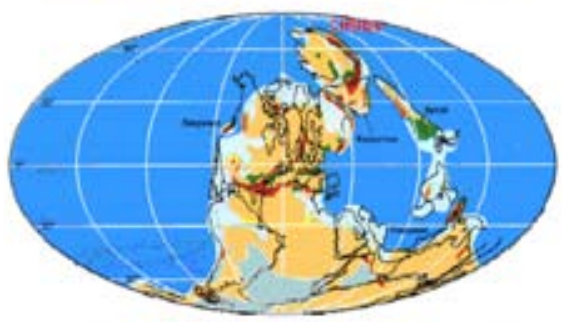

300-286 млн лет назад (Карбон)

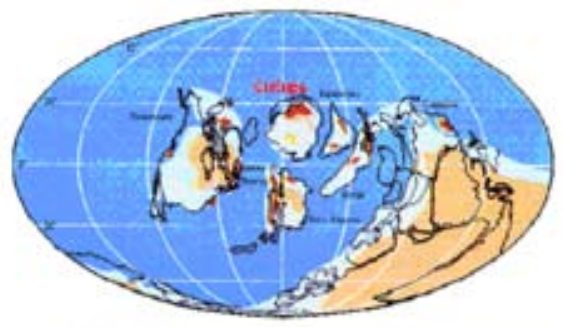

448-438 млн лет назад(Ордовик)

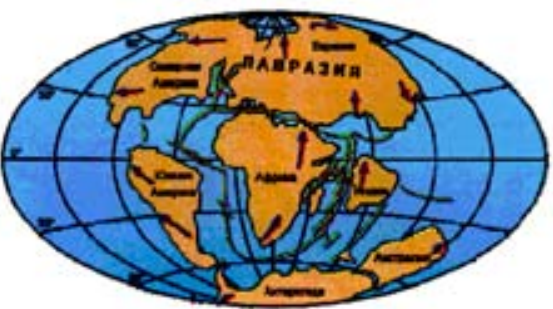

144-65 млн лет назад(Мел)

Рис. 1. Дрейф континентов по Вегенеру (Ушаков, Ясаманов, 1984)

столетия для 134 метеостанций, расположенных на территории Сибири и Дальнего Востока (Ипполитов, Кабанов, Комаров, Кусков, 2004). По результатам вычислений на карте строились изолинии для линейных трендов. На рис. 2 приведена карта пространственного распределения величины этих трендов для Сибири. Изолинии на карте выделяют районы с разной величиной тренда (разная степень зачернения) через 0,1 градус потепления за 10 лет. Как видно на рис. 2, на всей территории Сибири темпы потепления во второй половине XX в. были довольно высокими (более 0,2 град/10 лет), а в отдельных районах достигали величины линейного тренда в 0,5 град/10 лет. Подобные районы можно назвать очагами ускоренного потепления. Мезомасштабные по размерам, они сосредоточены прежде всего в Восточной Сибири и, как следует из анализа среднемесячных температур, обусловлены повышением температур в зимние месяцы (Ипполитов, Кабанов, Комаров, Кусков, 2004).

Из сравнения карты потепления на рис. 2 с данными Климатического атласа СССР
(1961 г.) за 1881-1935 гг. следует, что в последние десятилетия за счет очагов ускоренного потепления выравнивается зональность температурного режима в Сибири. Штриховые линии на рис. 2 соответствуют среднемесячным температурам января (минус $28^{\circ} \mathrm{C}$ и минус $20^{\circ} \mathrm{C}$ ) по Климатическому атласу СССР и разделяют районы Сибири на более холодные (к северу от штриховых линий) и более теплые (к югу от штриховых линий). При этом штриховые линии достаточно близко описывают контур тех районов, в которых находятся очаги ускоренного потепления.

Наблюдаемая тенденция к выравниванию широтной зональности для приземной температуры в Сибири может быть объяснена эволюцией режима атмосферной циркуляции в последние десятилетия. Действительно, выполненный анализ пространственных характеристик поля давления, определяющего режим атмосферной циркуляции (Вакуленко, Монин, Шишков, 2000), показал (рис. 3), что практически над всей территорией Сибири давление за исследуемый период уменьшалось со скоростью 0,2-0,4 гПа/10 лет, достаточной для 


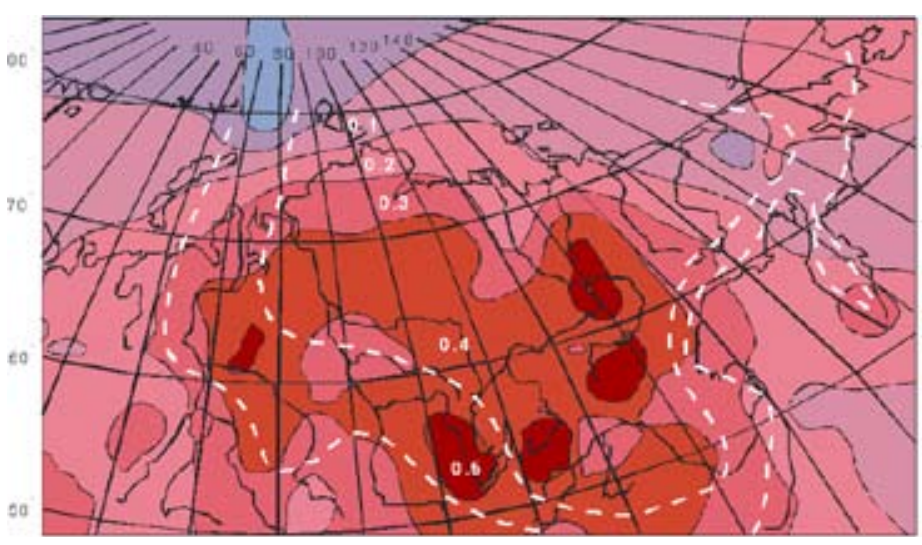

Рис. 2. Карта линейных трендов потепления в период 1965-2000 гг. Сравнение с изолиниями января (минус $28^{\circ} \mathrm{C}$ - верхняя, и минус $20^{\circ} \mathrm{C}$ - нижняя) в период 1881-1935 гг.

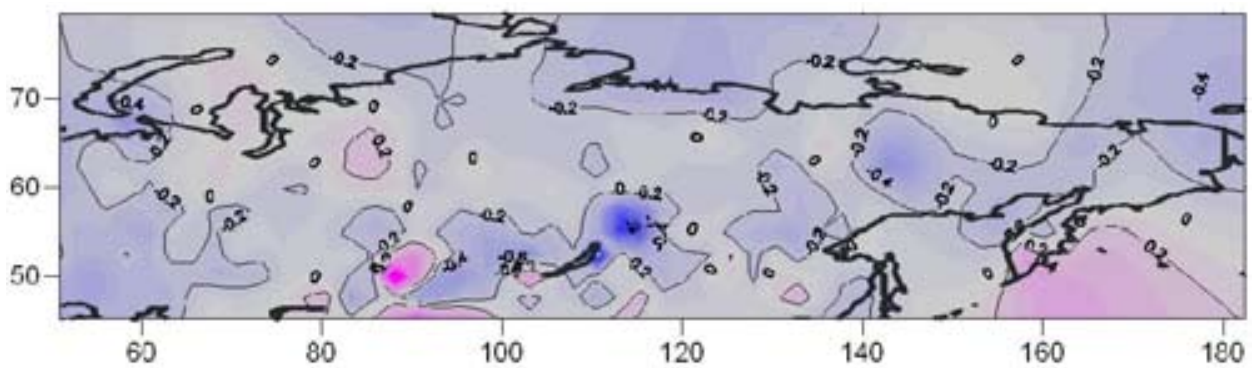

Рис. 3. Карта линейных трендов среднегодового приземного давления за период 1975-2005 гг. по данным наблюдений (гПа/10 лет)

интенсификации процессов циклонической активности (Ипполитов, Кабанов, Логинов, 2005). В частности, как показал статистический анализ, в климатический период 19762004 гг. среднее отношение чисел циклонов и антициклонов равнялось 1,4 вместо 1,7 для климатического периода до 1975 г.

Предложенное объяснение согласуется с результатами исследований динамики атмосферной циркуляции в Северном полушарии, среди которых отмечен рост индекса меридиональной южной циркуляции и снижение индекса северной циркуляции в XX в. (Бышев, Кононова, Нейман, Романов, 2002).

\section{Масштабы наблюдаемой временной изменчивости}

Масштабы временной изменчивости наблюдаемого потепления в Сибири выявля- лись с использованием методик, основанных на применении вейвлет-анализа, показавшего свою эффективность при обработке многомасштабных сигналов и полей (Астафьева, 1996). В отличие от преобразования Фурье в данном случае используются локальные базисные функции, что позволяет не только определять структуру временного ряда, но и отслеживать динамику его составляющих. Для иллюстрации получаемых результатов анализа на рис. 4 представлен вейвлетспектр временного ряда в 120 лет для среднегодовых приземных температур в Томске (Ипполитов, Кабанов, Логинов, 2007). На рис. 4 приведены абсолютные значения коэффициента вейвлет-преобразования и отчетливо выделяются более темные области для периодичностей с более высокой амплитудой. 
На рис. 4 видно, что статистически значимые масштабы периодичностей в этом анализируемом временном ряде не только присутствуют, но и эволюционируют. Так, например, декадные периодичности, т.е. периодичности с масштабами колебаний в 10 лет, трансформировались в более мелкие периодичности с масштабами размером в 5-7 лет в конце XIX и во второй половине XX столетия. Периодичности с масштабами колебаний в 20-30 лет в течение XX в. постепенно трансформировались в периодичности с масштабами 15 лет с тенденцией к уменьшению, а также в периодичности с размерами масштабов 30-40 лет к концу века. Из приведенного рисунка и из сравнения аналогичных вейвлет-спектров рядов приземной температуры для нескольких городов Сибири (Ипполитов, Кабанов, Логинов, 2002) следует, что продолжающаяся трансформация статистически значимых периодичностей происходила в XX в. одновременно для всего Сибирского региона и может быть объяснена сменой роли глобальных климатообразующих факторов.

Для выявления роли глобальных природных процессов в трансформации временных периодичностей наблюдаемого потепления в регионе был проведен корреляционный анализ между вейвлет-спектрами среднегодовых температур на территории Западной Сибири и вейвлет-спектрами такого планетарного индекса, характеризующего атмосферную циркуляцию, как Северо-Атлантическое колебание (NAO).

На рис. 5 показаны результаты вейвлеткорреляционного анализа для временных рядов приземной температуры и индекса NAO. На этом рисунке сверху представлена временная динамика коэффициентов корреляции между периодичностями разных масштабов. Статистически значимые величины коэффи-

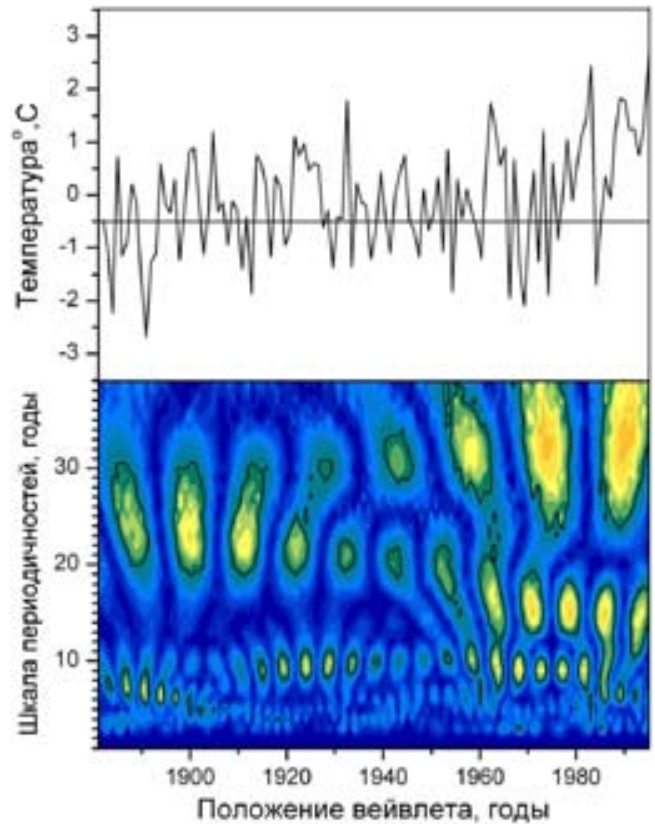

Рис. 4. Ряд среднегодовой температуры (вверху) и его вейвлет-спектр (внизу) для г. Томска

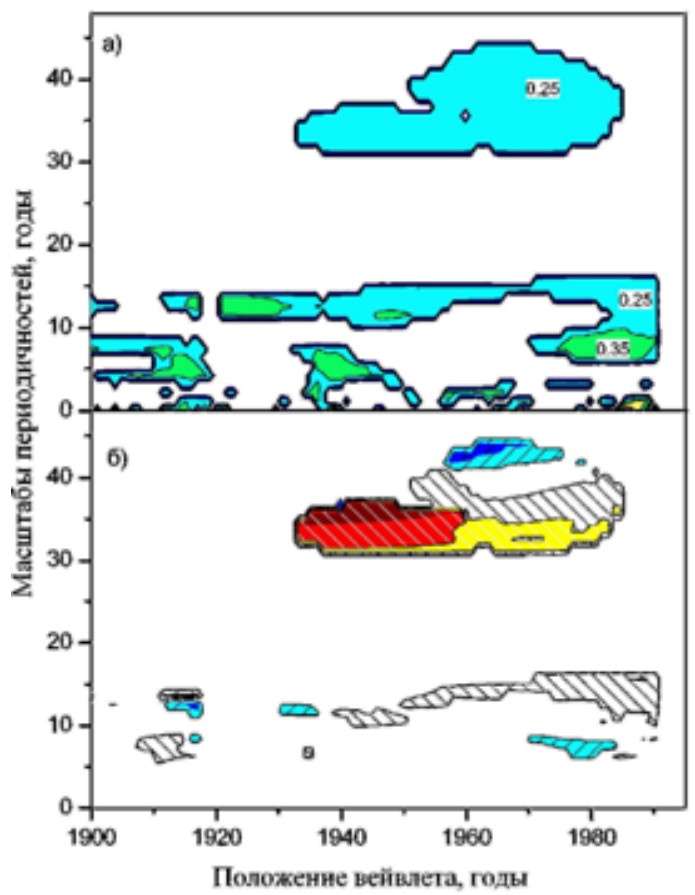

Рис. 5. Корреляция вейвлет-спектров между среднегодовой приземной температурой $\mathrm{T}$ и индексом NAO: a - коэффициенты корреляции вейвлет-спектров (изолинии с шагом 0,1; максимальная величина 0,5); б - фазовые сдвиги для вейвлет-спектров (изолинии с шагом 2 года, максимальная величина 7 лет) 
циентов корреляции (более 0,3 ) отмечены разной штриховкой. Внизу на рис. 5 для коррелируемых периодичностей приведены фазовые сдвиги, величина которых также обозначена разной штриховкой. Фазовые сдвиги для периодичностей малых масштабов (5-7 лет) отсутствуют, для периодичностей средних масштабов (10-15 лет) составляют 1-3 года, а для периодичностей большого масштаба (30-40 лет) увеличиваются до 7 лет.

Особый интерес представляет временная корреляция для одиночной периодичности с масштабом в 30-40 лет. Выявленная периодичность с повышенной вейвлет-корреляцией в 40-80-е гг. прошлого столетия может рассматриваться как климатический феномен этого временного периода. Этот феномен имеет важное методологическое значение для описания климатических изменений, так как указывает на необходимость дифференцированного описания климатических процессов, формирующих климат, и погодных процессов, формирующих погоду.

\section{Климатические особенности}

\section{для болотных экосистем (на примере}

\section{Большого Васюганского болота)}

Такие природные гидросферные образования, как водно-болотные угодья, занимающие значительную часть территории Сибири, особенно интересны для исследований наблюдаемых климатических изменений. Это связано не только с возможностью специфических последствий глобальных изменений, но и с тем влиянием, которое эти образования могут оказать на региональные климатические процессы, а через них и на глобальные. Выбранное для исследований Большое Васюганское болото (БВБ) является крупнейшим в мире по занимаемой площади и имеет многие другие рекордные показатели, указанные в таблице.

\begin{tabular}{|c|c|c|}
\hline № & Показатель & $\begin{array}{c}\text { Известные } \\
\text { оценки }\end{array}$ \\
\hline 1 & $\begin{array}{l}\text { Общая площадь в Томской, } \\
\text { Омской и Новосибирской } \\
\text { областях }\end{array}$ & 53 тыс.кв. км \\
\hline 2 & $\begin{array}{l}\text { Преимущественный тип } \\
\text { болот }\end{array}$ & $\begin{array}{l}\text { грядово- } \\
\text { мочажинный, } \\
\text { сфагновый }\end{array}$ \\
\hline 3 & $\begin{array}{l}\text { Возраст болота, для 25\% } \\
\text { территории }\end{array}$ & $\begin{array}{l}\text { 6-10 тыс.лет, } \\
\text { более } 500 \text { лет }\end{array}$ \\
\hline 4 & Запасы воды в озерах & 400 куб. км \\
\hline 5 & $\begin{array}{l}\text { Tорфяные залежи: } \\
\text { разведанные запасы } \\
\text { средняя глубина } \\
\text { максимальная глубина }\end{array}$ & $\begin{array}{l}\text { более } 1 \text { млрд т } \\
2,4 \mathrm{M} \\
10 \mathrm{M}\end{array}$ \\
\hline
\end{tabular}

Результаты междисциплинарных исследований, проведенных в 1990-х гг. большой группой научных коллективов Сибирского отделения РАН и университетов Сибири, были обобщены в коллективном научном издании (Большое Васюганское болото..., 2002) со следующими разделами:

\section{- общая характеристика БВБ и при-} легающих территорий, включая описание основных этапов развития болотообразовательных процессов, а также культурно-исторических процессов в последние тысячелетия на этой территории;

- методологические основы регионального мониторинга и моделирования, включая обсуждение адаптированных и новых методических подходов к мониторингу и моделированию природно-климатических процессов на территории БВБ;

- современные природно-климатические изменения на территории БВБ, включая анализ наблюдаемых климатических, гидрологических, геохимических и атмосферных процессов;

- состояние и процессы развития природно-ресурсного потенциала БВБ, включая динамические аспекты 
торфообразования, почвообразования и ландшафтных структур на территории БВБ;

- освоение и охрана природных ресурсов, включая анализ состава ароматических углеводородов и липидов в торфозалежах, а также обоснование ландшафтного заказника в экосистеме БВБ на уровне мирового природного наследия.

Дальнейшие исследования, сосредоточенные на климатических особенностях БВБ, позволили получить ряд важных результатов, среди которых выделим три, связанных с климатообразующими и средообразующими процессами. Первый из этих результатов относится к выявленной цикличности процессов болотообразования, связанного с климатогенной природой торфонакопления за прошедшие тысячелетия (Годовой отчет..., 2006). На основании датировки стратиграфических колонок торфозалежи была получена временная зависимость скорости аккумуляции углерода в торфе за прошедшие 7 тыс.лет (вверху на рис. 6). Вейвлет-спектр этой зависимости приведен внизу на рис. 6. Здесь более светлые пятна соответствуют периодичностям с более высокой амплитудой коэффициента вейвлетпреобразования. Как видно из рис. 6, основные циклы периодичностей наблюдаются на всем исследованном интервале времени, но с изменением от 500 лет в прошлом до 1500 лет в настоящее время. Выявленная эволюция масштабов периодичностей по скорости аккумуляции углерода в торфе БВБ связывается с климатогенной природой торфонакопления и совпадает с результатами исследований в других регионах планеты (в Европе и Канаде (Yu, Vitt, Campbell, Apps, 2001). Из этого результата следует планетарный характер наблюдаемых эволюционных процессов, по крайней мере, для Северного полушария.
Второй важный результат связан с выявленными особенностями температурного поля на территории БВБ. Из-за отсутствия разветвленной наземной гидрометеорологической сети наблюдений на обширной территории БВБ для выявления неоднородностей температурного поля были использованы доступные результаты дистанционного зондирования со спутников. На рис. 7 (Большое Васюганское болото..., 2002) представлены высотные профили осредненной разности температур $\Delta \mathrm{T}=\mathrm{T}_{\mathrm{T}}-\mathrm{T}_{\mathrm{b}}$ в градусах Цельсия по данным спутника Sage. Профили среднемесячных $\mathrm{T}_{\mathrm{T}}$ и $\mathrm{T}_{\mathrm{b}}$ были получены пространственным осреднением данных по территориям размером $5^{\circ} \times 10^{\circ}$ ( $\mathrm{T}_{\mathrm{5}}$ - для территории БВБ, показанной на карте рис. 7) и временным осреднением данных за 5 лет (1988-2002 гг.).

Как видно на рис. 7, среднемесячные температуры для территории БВБ в отдельные месяцы отличаются от таковых для прилегающих территорий до $6{ }^{\circ} \mathrm{C}$. При этом наибольшие различия проявляются в июне (охлаждающий эффект) и в весенние месяцы (отепляющий эффект) как в приземном слое, так и на больших высотах (до 10 км). Анализ распределения поля температур на разных высотах по данным спектрометра MODIS для февраля 2004 г. (рис. 8, Кабанов, 2006) подтверждает наличие отепляющего эффекта болотной экосистемы в зимние месяцы и до больших высот.

Несмотря на то, что количественные оценки по абсолютным значениям наблюдаемых температур на рис. 7 и 8 отягощены возможными ошибками инструментального и методического характера, полученные результаты по относительным значениям не вызывают сомнений и могут быть использованы при обосновании территориальных масштабов комплексного климатоэкологического мониторинга и при моделировании региональных 

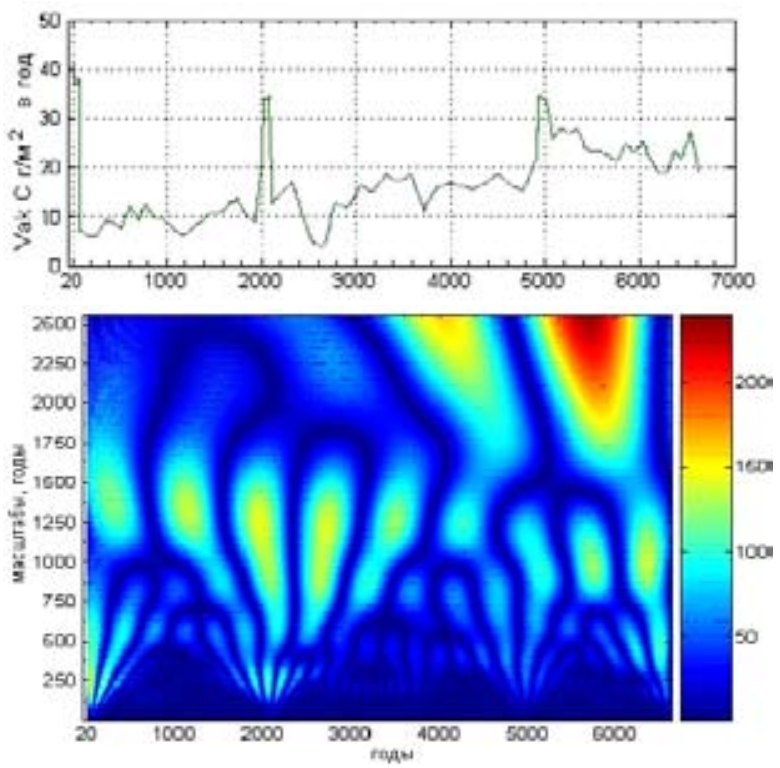

Рис. 6. Эволюция скорости аккумуляции углерода (Vak C) на северном участке БВБ

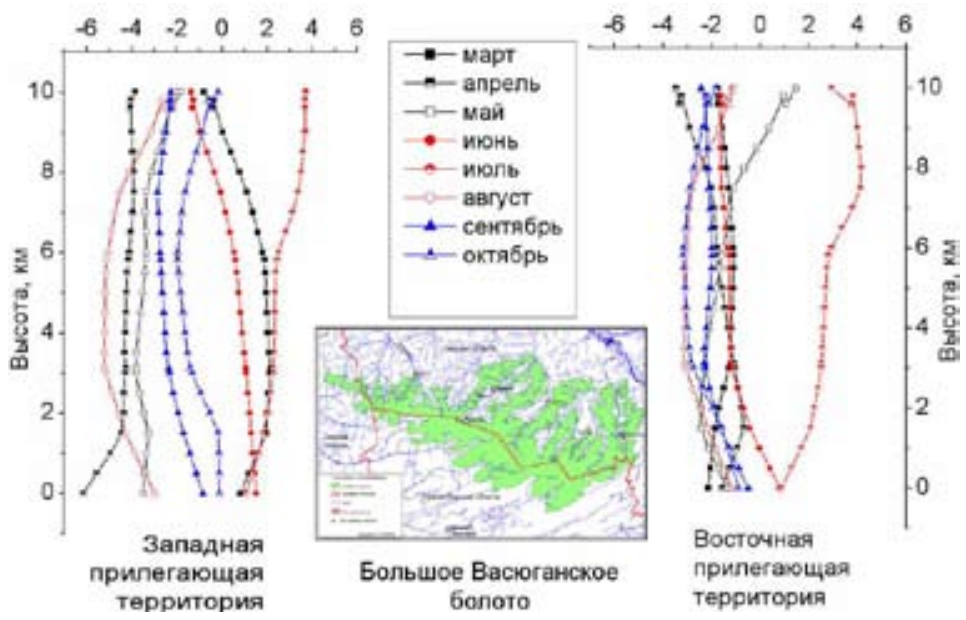

Рис. 7 Профиль разности осредненных по территории среднемесячных температур
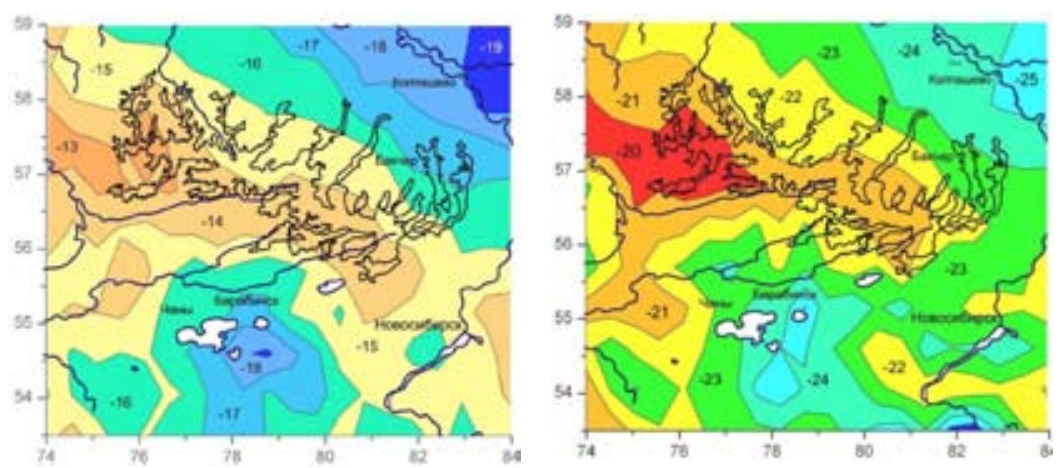

Рис. 8. Распределение поля температур на разных высотах над территорией БВБ (контурные очертания БВБ - в центре рисунка) 
климатических систем. В целом выявленные эффекты, которые следуют из рис. 7 и 8, пока не поддаются однозначной интерпретации и связаны скорее с теплофизическими свойствами торфозалежей, чем с эмиссионными потоками парниковых газов.

Третий результат получен на основании многолетних наземных наблюдений и связан с выявленной зависимостью эмиссионных потоков $\mathrm{CO}_{2}$ от ландшафтных и метеорологических условий. Статистический анализ одновременно измеряемых эмиссионных потоков $\mathrm{CO}_{2}$ с поверхности торфяной залежи

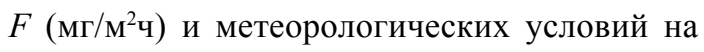
северном участке БВБ показал (Головацкая, Дюкарев, Ипполитов, Кабанов,2009), что эмпирическая зависимость $F$ от температуры воздуха $T\left({ }^{\circ} \mathrm{C}\right)$ и концентрации $\mathrm{CO}_{2}$ в атмосфере $C_{\mathrm{CO}_{2}}(\mathrm{ppm})$ удовлетворительно описывается формулой

$$
F=26,7+2,5 T-0,004 C_{\mathrm{CO}_{2}},
$$

а одновременно измеряемые эмиссионные потоки $\mathrm{CO}_{2}$ в точках с высоким и низким древостоем и на открытой топи различаются более чем в 2 раза (на открытых топях меньше). При этом углеродный баланс за счет эмиссии $\mathrm{CO}_{2}$ с поверхности торфа и депонирования $\mathrm{CO}_{2}$ фитомассой и торфом пока остается положительным для всех точек наблюдений. Более того, прогнозные оценки по полученным данным с учетом сценариев МГЭИК показали, что положительный углеродный баланс в части $\mathrm{CO}_{2}$ сохранится до 2080 года, несмотря на ограни- ченный потенциал болотной экосистемы по депонированию $\mathrm{CO}_{2}$.

\section{Заключение}

Из приведенного выше обзора по выявленным закономерностям природноклиматических изменений в Сибири следует ряд важных выводов, определяющих перспективы дальнейших интегрированных региональных исследований.

1. Существующие сети целевого мониторинга (гидрометеорологического, аэрозольнорадиационного, газопарникового и т.д.) необходимы, но недостаточны. С учетом взаимосвязи наблюдаемых глобальных и региональных факторов влияния на изменения окружающей среды и климата необходима специальная сеть комплексного мониторинга природно-климатических изменений.

2. Выявленная мезомасштабная неоднородность природно-климатических изменений на территории Сибири показывает, что сеть комплексного мониторинга должна быть географически распределенной и с учетом масштабов характерных экосистем Сибири (лесных, болотных, степных, горных, арктических и др.).

3. Инерционность отклика (фазовые сдвиги) региональных природно-климатических систем на глобальные факторы воздействия указывает на необходимость сопряженного регламента по мониторингу региональных погодных, климатических, экосистемных) и глобальных процессов.

\section{Список литературы}

Астафьева Н.М. (1996). Вейвлет-анализ: основы теории и примеры применения //Успехи физических наук, т. 166. № 11: 1145-1170.

Большое Васюганское болото. Современное состояние и процессы развития (2002) /Под ред. М.В. Кабанова, Томск, 229 с.

Бышев В.И., Кононова Н.К., Нейман В.Г., Романов Ю.А. (2002). Особенности динамики климата Северного полушария в ХХ столетии, т. 384. № 5: 674-681. 
Вакуленко Н.В., Монин А.С., Шишков Ю.А. (2000) Об изменениях общей циркуляции атмосферы в ХХ веке, т. 371. № 6: 802-805.

Годовой отчет ИМКЭС СО РАН за 2006 г. (Соавторы цитируемого результата: В.А. Крутиков, Ю.И. Прейс).

Головацкая Е.А., Дюкарев Е.А., Ипполитов И.И., Кабанов М.В. (2008) Влияние ландшафтных и гидрометеорологических условий на эмиссию $\mathrm{CO}_{2}$ в торфоболотных экосистемах //ДАН, т.412,№ 6: 814-817.

Ипполитов И.И., Кабанов М.В., Комаров А.И., Кусков А.И. (2004) Современные природноклиматические изменения в Сибири: ход среднегодовых приземных температур и давления // География и природные ресурсы. 3: 90-96.

Ипполитов И.И., Кабанов М.В., Логинов С.В.(2002). Вейвлет-преобразования при анализе природно-клматических изменений //Оптика атмосферы и океана. 1: 21-28.

Ипполитов И.И., Кабанов М.В., Логинов С.В. (2005) Закономерности современных природно-климатических изменений в Сибири: периодичность приземных температур, давления и некоторых геофизических индексов //География и природные ресурсы. 1: 13-20.

Ипполитов И.И., Кабанов М.В., Логинов С.В. (2007). Пространственные и временные масштабы наблюдаемого потепления в Сибири, т. 412, № 6, с. 814-817.

Кабанов М.В. (2006) Региональные аспекты современной климатологии по результатам анализа наблюдаемых природно-климатических изменений в Сибири //Оптика атмосферы и океана, т.16, № 11: 927-933.

Кабанов М.В., Лыкосов В.Н. (2006) Мониторинг и моделирование природно-климатических изменений в Сибири //Оптика атмосферы и океана, т.19, №9: 753-764.

Подобина В.М., Родыгин С.А. (2000) Историческая геология: учебное пособие / Издательство ТГУ, Томск, $262 \mathrm{c.}$

Трубицын В.П. (2005) Тектоника плавающих континентов //Вестник РАН, т. 75, № 1: 10-21.

Ушаков С.А., Ясаманов Н.А. (1984) Дрейф материков и климаты Земли. М.: Мысль, 206 с.

Yu Z.C., Vitt D.H., Campbell I.D., Apps M.J. (2001) Proceedings of International Field Symposium «West Siberian peatlands and carbon cycle: past and present». Noyabrsk, pp.152-154.

International Geosphere - Biosphere Programm II. Special Edition Issue, IGBP Newsletter/ №50, June 2002. $52 \mathrm{p}$.

Monroe J.S., Wicander R. (1994) The Changing Earth Explosing. Geology and Evolution. West Publ.Co., 731 p. 


\title{
Some Regularities in Climatic and Ecosystem Changes in Siberia
}

\author{
Mikhail V. Kabanov \\ Institute of Monitoring of Climatic and Ecological Systems, \\ Siberian Branch of the Russian Academy of Science \\ 10/3 Akademichesky, Tomsk, 634055 Russia
}

\begin{abstract}
Applying statistical analysis to instrumented data accumulated in the world meteorological network, we revealed regularities of climatic and ecosystems changes observed in Siberian region. It was shown that warming, observed in Siberia over last climatic period (30 years), is characterized by inhomogeneous subregional structure with mesoscale spots having accelerated warming rates up to $0.5{ }^{\circ} \mathrm{C} / 10$ years. Trends of surface pressure for the same period have lesser contrast subregional structure with decrease of annual mean pressure down to 0.2-0.4 hPa/10 years.

Wavelet analysis applied to time variability of climatic parameters over the past century found out periodicities with the scales of 10-12 and 30-50 years. Comparing wavelet spectra of surface temperature in West Siberia and North-Atlantic Oscillation index, we revealed their correlation in 1940-1990 with time shift up to 7 years. This climatic phenomenon could be explained by possible inertia mechanisms in oceanic heat transfer.

Based on results of ground and airborne and spaceborne instrumented observations, we discuss climatic influence of Siberian bogs (using Great Vasyugan Bog as an example).

Keywords: climate changes, ecosystem changes, warming map, wavelet analysis, Great Vasyugan Bog.
\end{abstract}

